\title{
Article \\ Study Abroad in Sweden: Japanese Exchange Students' Perspectives of Language Use in University EMI Courses
}

\author{
Aki Siegel ${ }^{1,2}$ (D) \\ 1 Department of English, Uppsala University, 75120 Uppsala, Sweden; aki.siegel@engelska.uu.se \\ 2 Department of Languages, Linnaeus University, 35195 Växjö, Sweden
}

check for

updates

Citation: Siegel, Aki. 2022. Study Abroad in Sweden: Japanese Exchange Students' Perspectives of Language Use in University EMI Courses. Languages 7: 3. https:// doi.org/10.3390/languages7010003

Academic Editors: Pia Sundqvist, Erica Sandlund, Marie Källkvist and Henrik Gyllstad

Received: 7 September 2021

Accepted: 21 December 2021

Published: 28 December 2021

Publisher's Note: MDPI stays neutral with regard to jurisdictional claims in published maps and institutional affiliations.

Copyright: (C) 2021 by the author. Licensee MDPI, Basel, Switzerland. This article is an open access article distributed under the terms and conditions of the Creative Commons Attribution (CC BY) license (https:// creativecommons.org/licenses/by/ $4.0 /)$.

\begin{abstract}
With the availability of English as a Medium of Instruction (EMI) courses, an increasing number of international students have been joining Swedish universities. However, the language use in Swedish EMI courses may display unique features; while many Swedish students have high English language proficiency, code-switching between Swedish and English is reported as a common practice by both lecturers and students, even when international students are present. Moreover, the term "international students" is often used to include students of various statuses and linguistic abilities, and the experiences and perspectives of short-term exchange students towards the language use in Swedish EMI courses are rarely documented. The current study investigates the perspectives of short-term exchange students from Japan enrolled in EMI courses at a university in Sweden. Questionnaire and focus group interview confirmed previous studies regarding the language-use practices in the classrooms. Moreover, the rate of speech, turn-taking, and background knowledge were found to hinder the learning and participation of the exchange students. The findings suggest the need to raise awareness of the language practices in Swedish EMI courses to students, lecturers, and other universities in order to support the learning experience of short-term exchange students.
\end{abstract}

Keywords: English as a Medium of Instruction (EMI); English as a Medium of Education (EME); study abroad; English as a Lingua Franca (ELF); multilingual classroom

\section{Introduction}

Before 2019, study abroad had been steadily increasing over the years and around the world. According to the International Organisation for Economic Co-operation and Development (OECD), the number of international students in higher education worldwide was 5.6 million in 2018, double the number for 2005 (OECD 2021). Sweden is not an exception. In 2019, there were approximately 40,000 students studying abroad in Swedish universities, a 3\% increase from the year before (SCB 2020). Students coming from Japan to Sweden, who are the target group of investigation for this study, were also on a steady increase with 348 students in 2019, of which 277 were identified as exchange students (SCB 2020). Although currently a small group of students, an increase can be expected in the number students from Japan in Sweden due to the increasing interest in studying abroad and more universities in Japan making overseas study a requirement for a bachelor's degree (Take and Shoraku 2018).

The increase in the number of students studying abroad in Sweden could partly be attributed to the internationalization efforts made by the universities to increase the number of international lecturers and students (Government Offices of Sweden 2018). Some of the motivation to internationalize universities stems from universities' strategies in increasing international visibility through university rankings and improving the education and quality of learning at the university level (Government Offices of Sweden 2018). In addition, attracting international students, especially from outside the EU/EEA system, has economic benefits that cannot be ignored. According to the Swedish Higher Education 
Authority (2018), there have been yearly increases in tuition fee revenues paid by students outside of the EU/EEA and Switzerland, totaling 687 million Swedish krona (SEK) in 2017.

One of the internationalization efforts that universities around the globe have undertaken is to offer more English as a Medium of Instruction (EMI) courses (Murata 2018). EMI refers to "the use of English language to teach academic subjects other than English itself in countries or jurisdictions where the first language of the majority of the population is not English" (Macaro 2018, p. 19). Moreover, I use EMI to include not only lectures, but also other classroom-related activities such as presentations and group discussions. In theory, EMI courses provide not only contents of subjects, but also opportunities to improve the students' English language abilities (Galloway 2020).

EMI courses have existed in Sweden for over 20 years (Kuteeva 2018), and in recent years, almost a third of lectures at Swedish universities are now conducted in English (Forsberg 2018). These EMI courses bring more opportunities for students outside of Sweden to join Swedish university programs, which aligns with internationalization plans that many universities have presented and are implementing (Government Offices of Sweden 2018).

However, studies of EMI courses in Swedish higher education have dismissed the perspective of short-term exchange students, who study abroad for one year or less, and their experience of this unique language-use environment. The term "international students" is often used in the EMI literature, but it is used as an umbrella term to include students of various statuses and linguistic abilities (e.g., Kuteeva et al. 2015). For instance, short-term exchange students will have limited Swedish abilities and limited time to adapt to the learning context compared to full-time degree students from abroad or non-Swedish students who have been living in Sweden for several years. Moreover, Danish or German speaking exchange students will have a relative ease of learning and understanding Swedish compared to students from Asia (e.g., Kuteeva 2020). Combining students with different linguistic and educational backgrounds into one umbrella term of "international students" limits our understanding of the issues various groups face, especially short-term exchange students with relatively low language proficiency in English and Swedish.

The study therefore aims to deepen our understanding of the linguistic experience of short-term exchange students attending EMI courses at a university in Sweden, and considers the ways in which programs can enhance the learning experience of these students. In particular, the study focuses on exchange students from Japan, who are increasingly interested in studying abroad in Scandinavia (SCB 2020). The study, therefore, poses the following research questions:

1. What are the Japanese short-term exchange students' attitudes towards the language use in EMI courses at a Swedish university?

2. Are there language practices in the classroom that hinder the learning of the Japanese short-term exchange students?

\section{Literature Review}

\subsection{English as a Medium of Instruction (EMI) in Sweden}

As mentioned above, EMI courses are educational contexts in higher education where English language is used to teach and learn academic subjects in countries where English is not the first language (L1) of the community (Macaro 2018). In EMI courses, lectures, student presentations, and peer interactions are conducted or encouraged to be conducted in English. Course materials including reading assignments and lecture slides also are often in English. The expectation that many students have towards EMI courses is that they will be able to learn the content of a subject while improving their English language proficiency (Rose and Galloway 2019).

EMI in Sweden, however, may display different features compared to other countries due to its "parallel language use" (Nordic Council of Ministers 2007) policy in the classrooms. Parallel language use refers to the policy presented in the Declaration on a Nordic Language Policy (Nordic Council of Ministers 2007, p. 13) developed by ministers for 
education and culture and other governmental representatives from the Nordic countries (e.g., Denmark, Finland, Iceland, Norway, and Sweden). The policy states that both Nordic languages and English should be used as languages of science, thus, the teaching of science should be offered in both English and in Nordic languages. In other words, students and lecturers in Nordic universities have the right to use the local Nordic language in the classroom regardless of it being an EMI course. As a result, EMI studies in the Nordic countries have frequently found code-switching between English and the local Nordic language by teachers and students (e.g., Ljosland 2014 in Norway; Söderlundh 2013b, 2014 in Sweden; Mortensen 2014 in Denmark).

At universities in Sweden, Söderlundh (2014) argues that Swedish is often used as the "default language" inside and outside of the EMI classroom, during group discussions and questions to teachers in front of the class. Ethnographic studies of Swedish EMI courses have also found teachers and students displaying preference towards Swedish in the EMI courses (e.g., Airey 2011; Kuteeva 2014; Airey and Linder 2006), and using Swedish even when "international students" were present (Söderlundh 2014). This is not to say that all Swedish students' English language proficiency is low. Swedish speakers are known to have overall high English language proficiency (Education First 2020), and some Swedish university students' reading comprehension abilities are found to be even better than L1 English users (Shaw and McMillion 2008). Rather, some studies report that English is often positioned as "the language of exchange students" by the Swedish students and lecturers (e.g., Söderlundh 2013a, 2013b, 2014). What this means is that Swedish students and lecturers do not see the need to speak English between Swedish speakers, and see English as a tool for communicating between speakers who do not speak Swedish. In turn, exchange students are "treated as English speaking students" (Söderlundh 2013b, p. 96) regardless of their L1s and English language proficiency.

However, as it will be discussed below, it is too simplistic to categorize international students as all the same "English speaking students", as there exist differences among the international students in terms of their English language proficiency that may cause friction among them.

\subsection{Student Challenges in EMI}

Despite the positive outcomes and potentials of EMI courses (Galloway 2020), there are challenges that students face in the classroom. These challenges are often regarding, but not limited to, students' language proficiency in English (e.g., Airey 2011; Airey and Linder 2006; Wilkinson and Yasuda 2013; Tsuneyoshi 2005) and content knowledge (Pessoa et al. 2014). For instance, Airey and his colleague found Swedish students being hesitant to ask and answer questions in English in front of the class, and displaying difficulty taking and reviewing notes when lectures were conducted in English (Airey 2011; Airey and Linder 2006). Moreover, Pessoa et al. (2014) reported on students having difficulties with reading comprehension not only due to a lack of vocabulary and reading stamina, but also background knowledge.

Student challenges could also be attributed to the English language proficiency of the lecturer and peers. Studies reported on students' difficulties in understanding lecturers' accents (Evans and Morrison 2011). There are also reports of lecturers providing less content when switching to English due to their lack of English language fluency (Tatzl 2011), such as students commenting that "everything is a bit slower" (p. 259) and the content is "reduced to $60-80 \%$ instead of $100 \%$ " (p. 259). However, the slower pace of lectures and reduced content could also be the teacher's intentional teaching strategy to avoid non-understanding and support the less proficient students (Galloway et al. 2017; Tatzl 2011).

International students who join EMI courses have their own challenges, such as the lack of the local language and low English language proficiency of the lecturers and peers. Code-switching to the local language is often reported in EMI courses (e.g., Galloway et al. 2017), but this can lead to the dissatisfaction of international students. For instance, 
Galloway et al. (2017) report an anecdote of an international student withdrawing from courses because the lecturer had low English language proficiency and spoke in the local language too frequently.

\subsection{Challenges of International Students in Swedish EMI}

The challenges that international students face in EMI courses are, in general, similar to what non-international students experience. However, international students who join Swedish universities have additional issues of the parallel language policy and the frequent use of the local language. EMI courses with parallel language use are not easy to navigate for students with limited Swedish ability.

Söderlundh (2013a), in her study examining six EMI courses, exemplified a situation where the lecturer responds to a student's request to translate a word into Swedish, but he continues talking in Swedish. When an exchange student coughs loudly to capture the lecturer's attention, the lecturer realizes that he needs to speak in English and switches back to English. However, not all exchange students have the courage to take such action in front of a class and to do "language-policing" (Amir and Musk 2013) of the lecturer. Not all exchange students may even have the language proficiency to follow the dialogue and know when and how to intervene.

Kuteeva (2020) investigated student attitudes towards English use in EMI courses and code-switching practices at a Swedish university through interviews. Although this was a small-scale study with only two local students and three international students, she similarly found that code-switching between Swedish and English was a common practice in student interactions. Moreover, she found that being able to speak Swedish granted the international students access to different student groups, including the "elite" Swedish student group, which was advantageous when completing group tasks. This finding resonates with other studies that find students having high proficiency in English and Swedish holds prestige in the university context (Hult 2012; Söderlundh 2013a). Söderlundh (2013a) writes, "native knowledge of English, or almost native knowledge, appears as the only truly, non-negotiable mobile linguistic resource at the international university" (p. 129). In other words, students who do not speak Swedish or English at a very high level of proficiency will struggle to join mainstream student groups and perhaps struggle to complete group tasks.

Kuteeva's (2020) study also touched upon a case where an international student shared her frustration towards another international student with lower English language proficiency who did not complete the group task due to non-understanding or misunderstanding. However, as Kuteeva (2020) admits, these international students with lower English language proficiency were not included in the study.

This is true with other EMI studies in Sweden. Frequently, "international students" in these EMI studies conducted in Sweden would often be multilingual students who speak both Swedish and English or be L1 or highly proficient English speakers from the US, India, or Germany (e.g., Kuteeva et al. 2015; Kuteeva 2020). The voices of international students with relatively low Swedish and English language proficiency are rarely heard in the EMI literature in Sweden. What are the attitudes and experiences of these students with the Swedish EMI courses? With an increasing number of students from Asia and the Middle East joining Swedish EMI programs, the perspectives of students with relatively low English language proficiency are becoming increasingly important.

The current study therefore aims to shed light on these unheard voices of international exchange students, who have relatively lower English and Swedish language proficiency, and examine what their experiences and attitudes are towards the EMI courses in Sweden.

\section{Methods}

The data collection took place at a university in southern Sweden. At the time of the data collection, the university had agreements with multiple Japanese universities, and approximately 40 exchange students were coming from Japan every year. In order to 
identify the language use and attitudes of Japanese exchange students towards the EMI courses at the university in Sweden, two methods were employed: student questionnaires and a focus group interview with students.

\subsection{Student Questionnaire}

A questionnaire was created based on the findings of studies mentioned above (e.g., Airey 2011; Evans and Morrison 2011; Galloway et al. 2017; Hult 2012; Söderlundh 2013a) to seek the perspectives of the Japanese students in terms of language use in the EMI classrooms. For example, the questions focused on seeking whether students had difficulty with the accents and code-switching by the lecturer and peers, as well as other difficulties they had experienced in the EMI classroom in terms of language use. The questions also aimed to highlight the needs the exchange students may have that may be particular to this group. The questions included a 4-point Likert scale question, a question that allowed multiple answers, and open-ended questions.

The questionnaire was distributed to the Japanese student groups through an online form. A total of 25 students completed the questionnaire: 11 students studying during the Spring term of 2019 and 14 students from the Fall term of 2019. No noticeable differences were found between the two groups in terms of their backgrounds. Therefore, the answers were combined. All participants were exchange students based on agreements between universities. Their self-reported English language proficiency test scores were between IELTS 5 and 6.5, with the mode being band score 6. At the time of the data collection, all exchange students were taking face-to-face classroom courses. For a quantitative study, 25 responses is a relatively low sample size. However, considering the total number of Japanese exchange students attending this university, I argue that the sample is a sufficient representation of this target population.

\subsection{Focus Group Interview}

After the questionnaire, a focus group interview was conducted with four students to gather in-depth experiences based on the responses from the questionnaire. Interviewees were recruited through an online message board for Japanese exchange students at the university, and the four students volunteered to participate in the interview. The researcher did not know these students prior to the interview. The questions focused on their language use in and outside the classroom, life on and off campus, and preparation before their study abroad. The interview was semi-structured with set questions that were then followed up with additional questions. The researcher had no contact with or knowledge of any of the lecturers or courses the participants were taking. Therefore, the participants may have felt more comfortable to share their honest perspectives on the EMI courses they were taking.

The interview lasted for approximately two hours. During the interview, I made sure that all students were given equal opportunities to express their opinions. The interview was transcribed and analyzed to seek connections to the findings from the questionnaire results and to identify new themes, if any.

Both the questionnaire and interview were conducted in Japanese in order to secure clarity. Therefore, the tables and quotes shown below are based on translations made by the author. The translated questionnaire questions are presented in Appendix A, and the translated interview questions can be found in Appendix B.

\section{Results}

The questionnaire and interview data were analyzed quantitatively and qualitatively, seeking patterns that arise from the data. I first begin by analyzing the findings from the questionnaire, focusing on the closed questions while using the answers from the open-ended questions to better understand the responses. I then moved on to analyze the findings from the focus group interview in the two major areas of EMI courses: group discussions and lectures. 


\subsection{Questionnaire}

Table 1 displays student responses on their attitudes of language use in Swedish classrooms. The statements students were asked to respond to are displayed on the left side of the table. Responses were on a four-point Likert scale as follows: 4- "strongly agree"; 3-"agree"; 2-“disagree"; 1-“"strongly disagree". The mean and standard deviation for each selected question is shown in the table.

Table 1. Language use in the Swedish EMI classroom.

\begin{tabular}{|c|c|c|c|}
\hline & Selected Questions & Mean & SD \\
\hline 1 & English is enough when communicating with lecturers & 3.32 & 0.56 \\
\hline 2 & English is enough when communicating with non-Swedish students & 3.20 & 0.71 \\
\hline 3 & I understand the English during lectures & 3.00 & 0.58 \\
\hline 4 & My English improved after studying abroad to Sweden & 2.92 & 0.76 \\
\hline 5 & English is enough when studying at a Swedish university & 2.80 & 0.65 \\
\hline 6 & English is enough when communicating with Swedish students & 2.76 & 0.83 \\
\hline 7 & My Swedish improved after studying abroad to Sweden & 2.68 & 0.95 \\
\hline 8 & English used by the lecturers is sometimes strange & 2.36 & 0.64 \\
\hline 9 & I need Swedish when communicating with students & 2.96 & 0.64 \\
\hline 10 & I need Swedish when studying at a Swedish university & 2.28 & 0.68 \\
\hline
\end{tabular}

As it can be seen, overall, the Japanese exchange students view English as a universal language in the university. Many students agree that English is enough when communicating with lecturers and non-Swedish students, with a mean of 3.32 for Q1 and 3.2 for Q2. Moreover, in general, the students do not see Swedish necessary when studying and communicating with students (Q9-10). However, what is interesting is that not all students agree that English is enough when studying at a Swedish university (Q5, mean 2.8). The reason for this is perhaps found in Q6 (mean 2.76) where students do not necessarily see that English is enough when communicating with Swedish students, thus implying the need for Swedish when communicating with the Swedish students.

The majority of the students indicate that they understand English during the lecture (Q3), with a mean of 3.0 points and a relatively low standard deviation of 0.58 . Moreover, there is a certain degree of agreement that the students believe their English improved through the EMI courses and study abroad (Q4, mean 2.92). Therefore, just from Table 1, it seems that, overall, the Japanese exchange students are engaged and learning through the EMI courses at the Swedish university.

However, the question focusing on the language issues paints a different picture of the experiences of these Japanese exchange students, and highlights the struggles the students experienced in the EMI courses. Table 2 summarizes the multiple answer question where students were asked which of the listed issues they had experienced during the EMI courses. A total of 15 items were presented as options, which were based on the findings from previous studies discussed in the literature review. 
Table 2. Language issues in Swedish EMI lectures.

\begin{tabular}{clcc}
\hline & \multicolumn{1}{c}{ Issues with EMI Lectures/Lecturers } & $n$ & $\%$ \\
\hline 1 & Uses a lot of technical English words & 14 & $56 \%$ \\
\hline 2 & Speaks English too fast & 13 & $52 \%$ \\
\hline 4 & Writes too much on the power point (in English) & 11 & $44 \%$ \\
\hline 5 & Has a strong English accent & 9 & $36 \%$ \\
\hline 6 & English grammar is sometimes incorrect & 7 & $28 \%$ \\
\hline 7 & Explanations are long & 5 & $20 \%$ \\
\hline 8 & Does not explain a lot & 5 & $20 \%$ \\
\hline 9 & Uses Swedish & 5 & $20 \%$ \\
\hline 10 & Does not translate after using Swedish & 3 & $12 \%$ \\
\hline 11 & Uses different English words from what I learned & 2 & $8 \%$ \\
\hline 12 & English word use is sometimes incorrect & 2 & $8 \%$ \\
\hline 13 & Uses Swedish for technical words & 1 & $4 \%$ \\
\hline 14 & Uses Swedish in power point slides & 1 & $4 \%$ \\
\hline 15 & No problem & 1 & $4 \%$ \\
\hline
\end{tabular}

What can be found from Table 2 is that the majority of the issues the Japanese exchange students experienced in the EMI courses could be attributed to their lack of English language proficiency. Overall, $56 \%$ of the respondents answered that they struggled with technical English words used by the lecturer (Q1), and 52\% answered that the lecturer spoke too fast $(\mathrm{Q} 2)$. One student commented that their lecturer had been teaching at a university in the US, and "the lecturer's English was very fast and it was very difficult to catch what was being said" (S17). This corresponds with what Macaro (2018) calls the "ostrich model" EMI course, where the instructor does not incorporate any language support into the teaching.

This lack of English language proficiency could be related to the responses for Q3 as well. It was found that $44 \%$ of the students indicated that there was too much writing on the PowerPoint slides, which caused issues for them during the EMI courses. Some students commented, "The lecturer just read out the PowerPoint and I did not feel the need to be in class" (S14) or "The teachers put as much information as possible into the PowerPoint and I was bewildered" (S6). This practice could have been undertaken to support the understanding of students in class, or even to support the lecturer with their English. Nevertheless, many of the exchange students saw this practice as problematic. One reason for the problem could be because of the difficulty of reading and listening at the same time, which has a higher cognitive demand. Moreover, if the student cannot understand a technical English word used in the PowerPoint, as indicated in Q1, this would also slow down their reading speed and comprehension. This is similar to what Airey and Linder (2006) reported with students expressing their difficulties listening to lectures and taking notes at the same time in EMI lectures, which is also a high-cognitive-demand activity.

In the open-ended question that asked what kind of study abroad preparations the participants were glad they did or they wished they had done, three students commented they were glad they had studied the subject in Japan. Two students, in contrast, commented that they wished they had studied technical words in their area of study in Swedish or English before the study abroad program. In other words, when a new concept and a new word were introduced at the same time, with a high rate of speech in the second language (L2), the exchange students demonstrated issues with understanding and learning. Thus, having some background knowledge to understand the concept or key terms in the L2 
would have reduced the cognitive load of the students, and supported the classroom learning experience of the students.

Several students commented that they appreciated lecturers who were supportive towards students with low English language proficiency, such as themselves. One student commented, "All the teachers were very proficient in their English, and they were kind enough to support students' English language mistakes. They would say 'ask me if you don't understand', recommended essay editing websites, or didn't force Japanese students who are not willing to speak English to answer questions" (S6). The teaching practice by this particular lecturer seems to follow the EMI model that sees language support as necessary and incorporates it into the course instruction (Airey and Linder 2006).

Unlike previous studies (e.g., Söderlundh 2013a, 2014), the use of Swedish was not raised as a substantial language issue in the EMI courses for the Japanese exchange students. There were only a handful of cases where students reported on the use of Swedish by the lecturer and teaching material as issues. However, as shown in Q9, Q13, and Q14, there were a few reports of lecturers using Swedish in the EMI course (4-12\%), and sometimes not providing translations after using Swedish (Q10, 4\%). One student commented, "In classes where there were a lot of Swedish students, the teacher used Swedish words and it made it difficult to understand" (S9). Another student commented, "I want all the Swedish in the slides to be translated into English" (S8). This is interesting since in Kuteeva (2014), she reports on a student complaining about having slides in English and the lecture in Swedish, as this was confusing for the Swedish students. Here, we find the opposite where the slides were partially in Swedish and the lecture was in English, and it was confusing for the exchange students. Perhaps the use of Swedish in the slides was meant to support the understanding of the Swedish students. Nevertheless, it caused issues with the non-Swedish-speaking exchange students.

What was reported to be a bigger issue in terms of language use was the variety of Englishes used in the classroom. In Q4, Q5, and Q6, we see that students (20-36\%) had issues with accents and the use of grammar of the lecturers. Some students commented in the questionnaire that, "The teacher had a strong accent that it was difficult to understand" (S9) or "The Swedish lectures did not have a strong accent and was easy to understand, but lecturers from other countries had a strong accent and it was sometimes difficult to understand" (S10). This is similar to the findings from Evans and Morrison (2011) where students expressed trouble understanding the lecturer's English because of the unfamiliar accents. One student even commented, "People have different accents" (S7), as if the student did not know this before coming to Sweden. From the questionnaire, it is difficult to know what type of accent caused students to have difficulty understanding the lectures. What can be said, however, is that some students were unfamiliar with the different variety of accents used by the lectures.

In connection to teaching style, Q7 and Q8 present conflicting results where some students feel the lecturer's explanation is too long while others feel it is not enough. There was not much more information that could be found regarding this point in the comments and nothing conclusive could be said. However, reviewing what was reported above, there seems to be a wide range of practices by lecturers in the EMI courses: (a) some lecturers show more support and understanding towards EFL exchange students than others, (b) some lecturers use non-inner circle accents and others do not, and (c) some lecturers use Swedish and others do not. The responses from the questionnaire highlight the different learning situations the exchange students are required to adapt to in a short given time using their limited L2 English abilities.

What I had not anticipated that emerged from the questionnaire responses were the challenges the exchange students faced during the group discussions. Previous research on Swedish EMI courses also investigated the language use during group discussions, but often emphasized the mutual intelligibility of the speakers (e.g., Björkman 2008). In the open-ended questions where participants were asked to share any issues they had in class, including lectures, group discussions, and assignments, seven out of the 25 respondents 
(28\%) commented on struggles they had during group work or group discussions. All seven of them indicated their surprise with the high English language proficiency of other students, despite them also being L2 speakers, and their struggles of not being able to contribute to the discussion despite wanting to. Student comments include: "The group discussion went forward without me saying anything. It's not that I don't have an opinion but I couldn't say it. I felt inferior" (S15), and "It's a challenge for me to keep up with the discussion with Swedish and German students. Even though they are also L2 speakers they speak almost as fluently as native speakers, and while I'm thinking what to say, the topic moves on to the next point" (S21). Other comments were similar, where students expressed their shock with the advanced level of English of the L2-speaking students in the Swedish EMI courses and the large discrepancy from their English language proficiencies.

Another issue that emerged through the open-ended questions, which is not frequently discussed in EMI research in Sweden, is the students' struggles with the reading materials. Although a minority, two students commented on the heavy reading load and their struggles. One student commented, "I have lessons for this course everyday. But I have two or more readings I have to do (everyday). It's a challenge" (S23). This aligns with findings from Pecorari et al. (2011) where the majority of the Swedish students taking EMI courses in Sweden also expressed struggles with textbooks written in English. These students expressed that it takes longer for them to read the English textbook than it would if it were written in Swedish. Thus, reading academic texts in English is an issue even for high English proficiency students in Sweden, and reading assignments need to be considered carefully by the EMI lecturers.

\subsection{Focus Group Interview}

In order to gather deeper insights into the experiences of these Japanese exchange students and to confirm the findings from the questionnaire, a focus group interview was conducted. Interviewees included the following four students: Ami, Ben, Chika, and Dai (all pseudonyms). Ami and Chika attended the same university in Japan, which was known for its EMI-oriented program. Therefore, the two students had been exposed to EMI courses before arriving in Sweden and had some confidence in their English language ability. Ben, in contrast, majored in Sports education in Japan and had not taken any English language courses at the university level before arriving in Sweden. He had low English language proficiency and low self-confidence in terms of English language use. Dai majored in English literature and had taken multiple English language proficiency courses in Japan. Therefore, although not being exposed to EMI courses before coming to Sweden, he had a moderate level of English language proficiency and confidence. The interviewees' information is summarized below in Table 3 .

Table 3. Interviewees.

\begin{tabular}{ccl}
\hline Pseudonyms & Length in Sweden & \multicolumn{1}{c}{ Major in Japan/Type of Program } \\
\hline Ami & 2nd term & International liberal studies (EMI program) \\
\hline Ben & 2nd term & Sports education (non-EMI program) \\
\hline Chika & 2nd term & International liberal studies (EMI program) \\
\hline Dai & 1st term & English literature (non-EMI program) \\
\hline
\end{tabular}

The aim of the focus group interview was to confirm the answers from the questionnaire and to seek a more detailed description of the students' experiences in Sweden. Therefore, the interview questions were not limited to questions about language use in the classroom, but also included questions regarding communication outside the classroom. However, for the purpose of this paper, I will focus on the responses related to classroom language use during group discussions and lectures. 


\subsubsection{Group Discussions}

When I asked the interviewees about what they felt, in general, about EMI courses in Sweden, the topic of group discussion came up immediately and throughout the whole interview. Some of the themes that were raised repeatedly by multiple interviewees regarding group discussions were their issues with: (a) the rate of speech, (b) turn-taking, and (c) background knowledge.

Ami and Chika both attended a university in Japan that was EMI program oriented. Therefore, they mentioned that EMI lectures in Sweden did not feel any different from the courses they had taken in Japan. However, the rate of speech by their peers was much faster than expected. Ami said, "They can say what they think in English directly. I have to think first and then make it into English. So I can't keep up with the conversation".

This rate of speech seemed to have also affected the turn-taking during group discussions. Even Ami and Chika, who had previous experience with group discussions, had trouble with turn-taking. Ami said, "There was this Swedish student in my group who was really into it, and we couldn't even slip a word in. The person, like, said everything". Chika agreed and said, "I tried to say something, but when I paused, the person next to me said everything (what I was going to say)". Ami and Chika mentioned that the group discussions they had participated in Japan were in English, but were at the pace of Japanese L2 English speakers; thus, these did not fully prepare them for such fast-paced group discussions.

Ben, who had little English language training before coming to Sweden, however, found his own strategy to cope with this high rate of speech and fast pace of turn taking. He mentioned that he would always prepare notes on what to say before class. Furthermore, he mentioned that Ami and Chika would help him find the right moment to say his prepared opinion during the group discussion. Ben said, "I had a cheat sheet", and "(Ami and Chika would tell me) Read this! Go!" Therefore, knowing the discussion questions and having ample time to prepare allowed Ben to participate in the group discussion despite his low language proficiency. What is interesting here is that, even if the students prepared for the group discussions with opinions to share and had some experience in conducting group discussions, they needed to know "when" and "how" to join a discussion at a fast speech rate. In other words, the interviewees were displaying trouble with turn-taking during multi-party talk, which has yet to be discussed as an academic skill that can be introduced in the language classroom (e.g., Ryan and Forrest 2021; Wong and Waring 2010).

Another point that affected the interviewee's participation seems to stem from differences in background knowledge. Ami said, "I didn't feel excluded because of my English, but I felt excluded because of my background knowledge". She continued to explain that most of the students in her class were from the EU, and thus, had plentiful knowledge regarding EU politics and history. However, as someone who was educated in Asia, there was a lot she did not know, and thus, she could not easily join the discussion. Dai also mentioned that sometimes the conversation would move on to discuss differences in education systems, scholarships, health insurance, and gender equality between countries, and that the topics were "difficult". This could be due to the lack of exposure to various topics through their English education in Japan (see Siegel 2014). However, Ami mentioned that, although feeling excluded, she was able to share her knowledge about Japan. Dai also mentioned that the more background knowledge he had, even if it was about Japan, the more he could talk and contribute to the discussion. Therefore, similar to the findings from the questionnaire, background knowledge seems to affect the engagement of the exchange students in the discussion, as well as their mental state of being "included" in the group.

Swedish use during group discussions was not raised as a major issue, but the interviewees reported that there was use of Swedish. Chika mentioned that, one time, everyone in the group was Swedish besides her. They were initially speaking English, but "when it got into more complex content and the discussion got heated up they went on speaking in Swedish. But if I asked, they would translate everything into English for me". Therefore, Swedish existed in the EMI group discussions, but the interviewees did not see it as a 
critical issue. Rather, being "included" in the group or not seemed to be a more important issue.

Ben mentioned that the Swedish students were "kind", but he was not confident about how they saw him as a group member when undertaking group work. Ben mentioned, "I didn't know what they thought of Japanese people. I felt I had to say something. Or else they won't know what I'm thinking or if I really understood what they were saying". Ami followed up and shared an episode; "I would ask what they just said, and they would say 'what?' and that facial expression is scary and I would feel 'I don't want to talk any more'". Ben agreed with this statement. Although this incident may be due to individual or cultural differences, it suggests the sensitive state the exchange students are in. That is, the exchange students are lacking the background knowledge and language ability (English and Swedish) to feel "included", and small misunderstandings with peers could affect their confidence and emotional state.

\subsubsection{Lectures}

With regard to lectures, all interviewees agreed that they understood the lectures (some more than others) and the lecturers' language was comprehensible. In terms of the use of Swedish, Dai mentioned that his lecturer almost exclusively spoke in English, probably because it was a course that many exchange students were taking. He also mentioned that the lecturer would sometimes fall back on Swedish, but would translate it into English. Ami and Ben also mentioned that in a course that was aimed at exchange students, the teacher was trying very hard to speak in English all the time, even using Google translate to find words in English. This aligns with studies that highlight lack of confidence and English proficiency of EMI lecturers (e.g., Dang et al. 2021; Galloway et al. 2017; Kim et al. 2018). However, the interviewees did not see the use of the translation device as negative; rather, took it as a positive action that the lecturer was doing their best to communicate in English.

None of the interviewees mentioned issues regarding reading assignments or having too much writing in the lecture slides. However, they appreciated having the lecture slides uploaded to an online platform after the lectures. Ben, in particular, mentioned how he would review the lecture using the uploaded slides and handouts and use them to complete his writing assignments. What we see here is that language use, teaching, and learning goes beyond the face-to-face lecture, and having materials available that students can refer to outside the classroom supports the students' learning process.

\section{Discussion}

\subsection{Summary of Findings}

The questionnaire and focus group interview helped address the questions related to the Japanese exchange students' attitudes (i.e., RQ1) and the issues (i.e., RQ2) regarding language use in the Swedish EMI courses.

In terms of student attitudes, the findings indicate that the exchange students, overall, understood the lectures and the lecturers' use of English. However, they had negative attitudes towards the overuse of technical words, fast rates of speech by lecturers and classmates, and dense writing on the lecture slides. The advanced English language proficiency of the Swedes and other European classmates and differences in background knowledge in some subject areas were a surprise to many of the participants. Due to these points, some felt "excluded" from the non-exchange student group, despite their efforts in terms of studying hard and attempting to communicate their ideas to others.

The issues the students faced in the classroom regarding language practices were connected with the negative attitudes raised above. The high rate of speech and the use of technical words was the most commonly mentioned issue. However, the interview result suggested that the issue is not necessarily the speed of comprehension, but the speed required to jump into the conversation to take their turn or to keep their turn during group discussions. Moreover, the issue with technical words was found to be connected to the 
lack of background knowledge and English language proficiency. Swedish use by lectures and peers was reported, similar to previous studies; however, it was not as frequently reported as in other studies. One reason for this could be because exchange students were taking some courses that were exclusively for exchange students. Nevertheless, the few who did report on Swedish use by the lecturer expressed issues with it.

\subsection{Voices of the Japanese Exchange Students}

Previous EMI studies in Sweden have displayed exchange students as being positioned as "problematic" by other students due to their low English language proficiency (e.g., Kuteeva 2020). The findings from the current study confirmed this, and the overall low language proficiency was found to hinder the exchange students' performance in the classroom and reduce their opportunities to become members of the university community (Wenger 1998). Looking at the relatively low IELTS scores of the Japanese exchange students (i.e., Band score 5-6.5), it is speculated that students with higher English language proficiencies usually go to the L1-English-speaking countries such as the US, the UK, and Australia for their exchange programs, and the relatively lower-proficiency students are coming to Sweden because it is an EFL country. What the students and universities in Japan are not aware of, before arriving, is the high English language proficiency of Swedes and the high expectations of the Swedish EMI courses. Moreover, it was reported that, in general, the Japanese education system is not preparing their students for EMI (Taguchi and Naganuma 2006).

However, as seen from the answers from the questionnaire, the Japanese exchange students have their own story. There are students who have EMI experience before arriving in Sweden, and have trained themselves for lectures and group discussions in English. There are students who, although trying their best, have limited English and academic capacity in what they can achieve and are struggling to keep up with lectures, discussions, and reading assignments. A student in the questionnaire summed up the situation of the Japanese exchange students: "I took EMI courses in Japan. I did discussions only in English. I read English articles and critically analyzed them. But after coming here, I can't participate in the discussion. I can't keep up with the heavy reading load. I can't understand what the teacher is saying. This situation is really shocking for me" (S21).

The blame cannot be placed just on the Japanese exchange students for their low performance. One student commented, "I didn't have much experience with discussion, and initially, I was worried and startled. But the lecturer instructed me step by step, and I got used to it". (S16). Therefore, as mentioned previously, there seems to be a range of practices employed by the EMI lecturers: those who acknowledge the linguistic support some students require and are able to provide it, and those who conduct EMI courses as if they are teaching L1 English students and/or students with high academic competence. Having EMI courses that employ the former approach, that is, with more linguistic support, the Japanese exchange students could possibly participate more and perform better in the EMI courses.

\subsection{Systemic Issues of Study Abroad in Sweden}

When considering how one can support exchange students to perform better in the Swedish EMI courses, there seem to be two systemic issues that are beyond the individual students' efforts that need to be addressed. The first issue is related to the ways in which Swedish universities are perceived by university administrators in Japan. Since Sweden is an EFL context, the language proficiency threshold for students to join the exchange program is apparently lower than going to L1-English-speaking countries. As a result, students with relatively lower English language proficiencies are accepted into Swedish universities, and they struggle to keep up with the advanced English language proficiency of their peers. Although the exchange program brings valuable experience to the exchange students in terms of being able to engage with students with higher levels of language and academic performance, universities may want to reassess the threshold of the English 
language proficiency requirements of students to avoid any false understanding of the expectations of the students. More awareness-raising of the Swedish learning context (i.e., highly proficient English speakers, European background knowledge) would benefit the exchange students as well.

The second issue is related to the ways in which educators perceive "EMI". There are various models of EMI and what it entails in terms of teaching practices, including language support (Galloway 2020). On one hand, the data illustrated that some lectures take the "concurrent support system" (Galloway 2020) where language support is provided in class, such as supporting group discussion skills, uploading materials online for review, and being available for questions. On the other hand, the findings demonstrated the "ostrich model" (Macaro 2018) being used, where there is no grading of language use by the lecturer (and peers), and there is no language support. The data also showed that the Japanese exchange students appreciated the former EMI model where language support was provided by lectures. This is not to say that all lecturers need to become language teachers, speak very slowly, and disregard the advanced level students who are capable of following the course. Instead, it indicates that lectures need to be aware of the various student backgrounds and proficiency levels, and if necessary, have a pre-requisite English language proficiency level, provide some form of learning support (e.g., provide the lecture slides before the lectures), and adjust their language as needed (e.g., avoid the overuse of technical words). This finding is consistent with a recent meta-analysis of studies on EMI educators in higher education where Dang et al. (2021) found most EMI educators did not perceive it as being their role to support the development of the students' English language abilities. The authors suggest that there is a need to "provide clarity and adequate support in negotiating the tensions from perceived roles and expectations of EMI educators" (p. 14).

The internationalization of universities brings together lecturers and students with various backgrounds, and creates opportunities for a rich learning experience. However, it also brings cases where a certain group of students cannot reach their full potential due to language-related issues. By bringing more awareness to systemic issues, as mentioned above, more exchange students could feel like and become members of the university learning community (Wenger 1998).

\subsection{Limitations of the Study}

The study, however, has its limitations. In particular, the questionnaire questions may have been unclear or phrased in a biased way. For example, a "strong accent" may have been interpreted or experienced in different ways, and some participants may have wished to choose an "unsure" option for the Likert scale question. Moreover, the phrasing of the question "What issues have you had with the lecturers' language use" presupposes existing issues and may have been a leading question, although there is a "no problem" option. Different phrasing of the questions may have led to slightly different outcomes of the questionnaire.

\section{Conclusions}

The current study problematized the lack of representation of short-term exchange students with limited English language ability in Swedish EMI literature, and brought to light the perspectives and experiences of Japanese exchange students attending EMI courses at a Swedish university. The questionnaire and focus group interview confirmed previous studies regarding the classroom practices of using Swedish and students with lower English language proficiency being excluded at times. More importantly, the study was able to highlight the strategies and efforts being made by the Japanese exchange students in order to contribute to the classroom discussions and complete the courses. Moreover, EMI course lecturers' teaching practices affected the confidence and self-reported performance of the exchange students. Although this study was small in its scale and limited in scope, it was able to exemplify research focusing on an under-represented group at the tertiary education level and their language practices in the classroom. With the increasing number of students 
with various learning backgrounds and language abilities joining higher education in Sweden, more investigations that have participants with a focused demographic can be beneficial in understanding what is actually happening in the classrooms and how learning can be maximized among the members of certain groups.

Funding: This study was supported by the Scandinavia-Japan Sasakawa Foundation: GA19-0413.

Institutional Review Board Statement: Not applicable.

Informed Consent Statement: Informed consent was obtained from all subjects involved in the study.

Data Availability Statement: No new data were created or analyzed in this study. Data sharing is not applicable to this article.

Conflicts of Interest: The author declares no conflict of interest. The funders had no role in the design of the study; in the collection, analyses, or interpretation of data; in the writing of the manuscript; or in the decision to publish the results.

\section{Appendix A. Questionnaire Questions}

Q1. Select the answer that best fits your views.

\begin{tabular}{|l|l|l|l|l|}
\hline & Strongly Agree & Agree & Disagree & $\begin{array}{c}\text { Strongly } \\
\text { Disagree }\end{array}$ \\
\hline I understand the English during lectures & & & & \\
\hline $\begin{array}{l}\text { English is enough when studying at a Swedish } \\
\text { university }\end{array}$ & & & & \\
\hline English is enough when living in Sweden & & & \\
\hline $\begin{array}{l}\text { English is enough when communicating with } \\
\text { Swedish students }\end{array}$ & & & & \\
\hline $\begin{array}{l}\text { English is enough when communicating with } \\
\text { non-Swedish students }\end{array}$ & & & & \\
\hline $\begin{array}{l}\text { English is enough when communicating with } \\
\text { lecturers }\end{array}$ & & & & \\
\hline $\begin{array}{l}\text { English is enough when communicating with } \\
\text { administration personnel }\end{array}$ & & & & \\
\hline $\begin{array}{l}\text { My English improved after studying abroad to } \\
\text { Sweden }\end{array}$ & & & & \\
\hline $\begin{array}{l}\text { My Swedish improved after studying abroad to } \\
\text { Sweden }\end{array}$ & & & & \\
\hline English used by the lecturers is sometimes strange & & & & \\
\hline English used by students is sometimes strange & & & & \\
\hline $\begin{array}{l}\text { Ineed Swedish when studying at a Swedish } \\
\text { university }\end{array}$ & & & & \\
\hline Ineed Swedish when living in Sweden & & & & \\
\hline Ineed Swedish when communicating with students & & & & \\
\hline
\end{tabular}

Q2. What issues have you had with the lecturers' language use (select all that apply).

Has a strong English accent

Uses an unfamiliar English accent

Speaking English too fast

Uses a lot of technical English words

Uses Swedish

Does not translate after using Swedish

Uses Swedish for technical words

English vocabulary is different from what I learned

English vocabulary is sometimes incorrect

English grammar is sometimes incorrect 
Uses Swedish in power points

Writes too much on the PowerPoint (in English)

Explanations are long

Does not explain a lot

No problems

Other (please specify)

Q3. What preparations did you do before studying abroad to Sweden that you found useful?

Q4. What preparations do you wish you had done before studying abroad to Sweden?

Q5. Describe in detail what you noticed about the language use in the classroom (lectures, discussions, etc.).

\section{Appendix B. Core Interview Questions}

- What are you studying in Japan?

- What kind of English classes did you take at your university in Japan?

- Why did you choose to come to a university in Sweden?

- What are you studying in Sweden? Which class are you taking?

- What are some issues you have in the classes?

- Do teachers/students use languages other than English? What would you do in that case? Does it cause any issues?

- How did you prepare for study abroad?

- What advice would you give to other students coming from Japan?

\section{References}

Airey, John. 2011. Talking about Teaching in English: Swedish University Lecturers' Experiences of Changing Teaching Language. Ibérica: Revista de la Asociación Europea de Lenguas para Fines Específicos (AELFE), pp. 35-54.

Airey, John, and Cedric Linder. 2006. Language and the experience of learning university physics in Sweden. European Journal of Physics 27: 553-60. [CrossRef]

Amir, Alia, and Nigel Musk. 2013. Language policing: Micro-level language policy-in-process in the foreign language classroom. Classroom Discourse 4: 151-67. [CrossRef]

Björkman, Beyza. 2008. English as the lingua franca of engineering: The morphosyntax of academic speech events. Nordic Journal of English Studies 7: 103-22. [CrossRef]

Dang, Thi Kim Anh, Gary Bonar, and Jiazhou Yao. 2021. Professional learning for educators teaching in English-medium-instruction in higher education: A systematic review. Teaching in Higher Education, 1-19. [CrossRef]

Education First. 2020. English Proficiency Index. Available online: https://www.ef.com/assetscdn/WIBIwq6RdJvcD9bc8RMd/ legacy/__ _ \{\}/media/centralefcom/epi/downloads/full-reports/v10/ef-epi-2020-english.pdf (accessed on 25 August 2021).

Evans, Stephen, and Bruce Morrison. 2011. Meeting the challenges of English-medium higher education: The first-year experience in Hong Kong. English for Specific Purposes 30: 198-208. [CrossRef]

Forsberg, Björn. 2018. Engelska allt vanlingare som undervisningsspråk [English is becoming more and more common as a language of instruction]. Universitetsläraren 8: 10.

Galloway, Nicola, ed. 2020. Teaching English English in Higher Education—English Medium Part 1: Literature Review. London: British Council.

Galloway, Nicola, Jaroslaw Kriukow, and Takuya Numajiri. 2017. Internationalisation, Higher Education and the Growing Demand for English: An Investigation into the English Medium of Instruction (EMI) Movement in China and Japan. ELT Research Paper 17.02. Available online: https:/ / www.teachingenglish.org.uk/sites/teacheng/files/H035\%20ELTRA\%20Internationalisation_ HE_and\%20the\%20growing\%20demand\%20for\%20English\%20A4_FINAL_WEB.pdf (accessed on 25 August 2021).

Government Offices of Sweden. 2018. Internationalisation of Swedish Higher Education and Research-A Strategic Agenda. Swedish Government Inquiries. Available online: https:/ /www.government.se/information-material/2018/02/internationalisation-ofswedish-higher-education-and-research--a-strategic-agenda/ (accessed on 25 August 2021).

Hult, Francis M. 2012. English as a transcultural language in Swedish policy and practice. TESOL Quarterly 46: 230-57. [CrossRef]

Kim, Jeongyeon, Eun Gyong Kim, and Soo-Ok Kweon. 2018. Challenges in implementing English-medium instruction: Perspectives of Humanities and Social Sciences professors teaching engineering students. English for Specific Purposes 51: 111-23. [CrossRef]

Kuteeva, Maria. 2014. The parallel language use of Swedish and English: The question of 'nativeness' in university policies and practices. Journal of Multilingual and Multicultural Development 35: 332-44. [CrossRef] 
Kuteeva, Maria. 2018. Researching English-medium instruction at Swedish universities: Developments over the past decade. In Medium Instruction from an English as a Lingua Franca Perspective: Exploring the Higher Education Context. Edited by Kumiko Murata. London: Routledge, pp. 46-63.

Kuteeva, Maria. 2020. Revisiting the 'E'in EMI: Students' perceptions of standard English, lingua franca and translingual practices. International Journal of Bilingual Education and Bilingualism 23: 287-300. [CrossRef]

Kuteeva, Maria, Niina Hynninen, and Mara Haslam. 2015. It's so natural to mix languages: Attitudes towards English medium instruction in Sweden. In Attitudes Towards English in Europe. Edited by Andrew Linn, Neil Bermel and Gibson Ferguson. Berlin: De Gruyter Mouton, pp. 193-212.

Ljosland, Ragnhild. 2014. Language planning confronted by everyday communication in the international university: The Norwegian case. Journal of Multilingual and Multicultural Development 35: 392-405. [CrossRef]

Macaro, Ernesto. 2018. English Medium Instruction. Oxford: Oxford University Press.

Mortensen, Janus. 2014. Language policy from below: Language choice in student project groups in a multilingual university setting. Journal of Multilingual and Multicultural Development 35: 425-42. [CrossRef]

Murata, Kumiko, ed. 2018. English-Medium Instruction from an English as a Lingua Franca Perspective: Exploring the Higher Education Context. London: Routledge.

Nordic Council of Ministers. 2007. Deklaration om Nordisk Språkpolitik 2006 [Declaration on Nordic Language Policy 2006]. Copenhagen: Nordic Council; Köpenhamn: Nordiska Ministerrådet.

OECD. 2021. Education at a Glance 2020 OECD Indicators. Available online: https:/ /www.oecd-ilibrary.org/deliver/69096873-en.pdf? itemId=\%2Fcontent\%2Fpublication\%2F69096873-en\&mimeType=pdf (accessed on 25 August 2021).

Pecorari, Diane, Philip Shaw, Hans Malmström, and Aileen Irvine. 2011. English textbooks in parallel language tertiary education. TESOL Quarterly 45: 313-33. [CrossRef]

Pessoa, Silvia, Ryan T. Miller, and David Kaufer. 2014. Students' challenges and development in the transition to academic writing at an English-medium university in Qatar. International Review of Applied Linguistics in Language Teaching 52: 127-56. [CrossRef]

Rose, Heath, and Nicola Galloway. 2019. Global Englishes for Language Teaching. Cambridge: Cambridge University Press.

Ryan, Jonathon, and Leslie Forrest. 2021. 'No chance to speak': Developing a pedagogical response to turn-taking problems. Innovation in Language Learning and Teaching 15: 103-16. [CrossRef]

SCB. 2020. Students from Abroad in Swedish Higher Education Academic Years 2009/10-2019/20, by Geographic Area, Country and Sex. Available online: https://www.scb.se/en/finding-statistics/statistics-by-subject-area/education-and-research/highereducation/international-student-mobility-in-higher-education/ (accessed on 25 August 2021).

Shaw, Philip, and Alan McMillion. 2008. Proficiency effects and compensation in advanced second-language reading. Nordic Journal of English Studies 7: 123-43. [CrossRef]

Söderlundh, Hedda. 2013a. Applying transnational strategies locally: English as a medium of instruction in Swedish higher education Nordic Journal of English Studies 12: 113-32. [CrossRef]

Söderlundh, Hedda. 2013b. Language choice and linguistic variation in classes nominally taught in English. In Language Alternation, Language Choice and Language Encounter in International Tertiary Education. Edited by Hartmut Haberland, Dorte Lønsmann and Bent Preisler. Dordrecht: Springer, pp. 85-102.

Söderlundh, Hedda. 2014. Zooming in on language practices in Swedish higher education: A discussion of five studies and their normative versus dynamic approach towards policy and practice. In English in Nordic Universities: Ideologies and Practices. Edited by Anna Kristina Hultgren, Frans Gregersen and Jacob Thøgersen. Amsterdam: John Benjamins Publishing Company, pp. 111-26.

Siegel, Aki. 2014. What should we talk about? The authenticity of textbook topics. ELT Journal 68: 363-75. [CrossRef]

Swedish Higher Education Authority. 2018. Higher Education in Sweden 2018 Status Report. Available online: https:/ / english.uka.se/ download/18.7f89790216483fb85588e86/1534509947612/Report-2018-06-26-higher-education-in-Sweden-2018.pdf (accessed on 25 August 2021).

Taguchi, Naoko, and Naeko Naganuma. 2006. Transition from learning English to learning in English: Students' perceived adjustment difficulties in an English-medium university in Japan. Asian EFL Journal 8: 52-73.

Take, Hiroko, and Ai Shoraku. 2018. Universities' Expectations for Study-Abroad Programs Fostering Internationalization: Educational Policies. Journal of Studies in International Education 22: 37-52. [CrossRef]

Tatzl, Dietmar. 2011. English-medium masters' programmes at an Austrian university of applied sciences: Attitudes, experiences and challenges. Journal of English for Academic Purposes 10: 252-70. [CrossRef]

Tsuneyoshi, Ryoko. 2005. Internationalization strategies in Japan: The dilemmas and possibilities of study abroad programs using English. Journal of Research in International Education 4: 65-86. [CrossRef]

Wenger, Etienne. 1998. Communities of Practice: Learning, Meaning, and Identity. New York: Cambridge University Press.

Wilkinson, Darrell, and Raymond Yasuda. 2013. The international program: Curriculum design and assessment for an English-medium economics program. The Asian EFL Journal Special Edition: CLIL in Asian Contexts: Emerging Trends 15: 347-54.

Wong, Jean, and Hansun Zhang Waring. 2010. Conversation Analysis and Second Language Pedagogy: A Guide for ESL/EFL Teachers. New York: Routledge. 